\title{
Comparative analysis of motivation theories
}

\author{
Zs. KISPÁL-VITAI \\ Faculty of Business and Economics of the University ofPécs, vitai@ktk.pte.hu
}

\begin{abstract}
The aim of the article is to compare motivation theories from the view of general psychology and work psychology. The research was done by using secondary sources and by analyzing motivation from both views. The difference between the two lines lies in outcome orientation. Psychology is more descriptive work psychology tends to focus on the results of the motivation process. In comparison, both have their values. The relevance of the research is to provide a theoretical basis for improving the development of more relevant motivation theories.
\end{abstract}

\section{Introduction}

Motivation seems to be one of the problems that have so many solutions as to have none at all. The concerns of individuals about their personal lives are full with issues of motivation. There are aims to achieve in the workplace; there are goals set by supervisors, bosses, markets and competitors, but these are not the only obstacles that humans face. In our private lives, we have to conquer desire for excess food, discipline ourselves to do sports to stay healthy, clean our living environment, give up bad habits, take medication, learn languages, the list of tasks is almost endless. All these activities are influenced by how much we want to do them, how fast we will convince ourselves to start, how long can our persistence last, how hard we are working with the activity and what are our feelings about the whole process. [Graham, Weiner, 1996] Motivation examines and tries to explain goal-directed behavior in people, why do we act in a certain way and why do we choose different modes of actions, especially when in a number of situations several possibilities of conduct are available.

Motivational research has a history of more than a century, results are abundant, and the number of theoretical approaches concerning motivation is overwhelming. There are coherent theories: systems of constructs that are linked logically together explaining why people behave as they do in what conditions and they also try to predict what happens if conditions will change. [Graham, Weiner, 1996, McAuley et al., 2007] There are also constructs: these are a cluster or domain of covarying behaviors [Binning, 2016] those are not linked together to a coherent theory but explain behaviour and also allow us to extrapolate future occurrences. Although researchers had done a considerable amount of work, both in the $20^{\text {th }}$ and now in the $21^{\text {st }}$ century,there isno universal solution to the motivation problem.In this article; we will examine some theories that were chosen based on a developmental approach: how much they contribute to our understanding of human behaviour. The first part of the article deals with general issues; then we will examine motivation theories and approaches considering general psychology and work psychology, in the third part we will contrast the two approaches and in the end we present some ideas that can be the basis for further research. 


\section{Problem desciption}

Motivation's question is a simple one: how do we achieve that people will start doing an activity, will persevere in it and keep doing it till the activity - and the person achieved the purpose of the pursuit. There arequite a few definitions that give us a good idea; here we will use two. The definition of psychology says:

"The factors that direct and energize the behavior of humans and other organisms." [Feldman, 2011]

Work psychology has a more complicated definition:

"Work motivation is a set of energetic forces that originate both within as well as beyond an individual's being, to initiate work - related behaviour, and to determine its form, direction intensity, and duration."[Pinder, 2008]

There are some examples of the energizing force of motivation and the astonishing results that one can achieve because of a motivated state of the individual. Feldman [2011, p. 309.] brings the example of Aron Ralston, the American outdoorsman and mountain climber who amputated his right arm because he had no other way of escape from a dislodged boulder. He survived and still goes mountaineering. In business history, the life of Steve Jobs, one of the founders of Apple computer is proof of unwavering motivation towards innovation. [Richardson, Terrel, 2008]

Motivation can save our lives, help us towards reaching our goals, can induce feelings of happiness, or the lack of motivation can give us trouble with unmet deadlines, pressing backlog of work, or unpleasant minutes of remorse about not keeping our diet. Explanation of causes of motivation would help both in individuals' personal lives and in work. If we had a clear idea of what induces goaldirectedbehavior, then we would be able to solve quite a few pressing problems in human life. Although the research was and is abundant about motivation, a clear-cut explanation is not available even good approximations may not be of any help in particular situations. We will examine motivation as it is studied in general psychology first, keeping in mind that work psychology is not a subdiscipline of psychology, it is applied psychology.

\section{Motivation in general psychology}

We base our analysis here mostly on Gősiné and Bányai, [2006], and Feldmann, [2011]. The reasons of behavior can be explained by two approaches: causal: what were events that induced activities.These events might be occurrences that happened in the past (eating too much caused becoming overweight), or biological or psychological causes (exercising helps to lose weight and makes us happy, so it is worthwhile to eat less and move). The other aspect is the goal-directed approach: we do something because the expected consequences are favourable for the action we choose (we will be polite in order to obtain a good opinion of ourselves).

According to the origin of the source of the force inducing the action,motivation can be extrinsic, or intrinsic. When the individual does something for an external reason such as learning a hard discipline because s/he wants to obtain a certificate, or doing the washing up because of wishing to secure the 
favorable opinion of the mother-in-law, then motivation is extrinsic. The reason of the action is different from what we do. When the individual does something because s/he enjoys doing it then,motivation is intrinsic. The person does it because it is fun, doing it causes happiness, joy; the reason is the activity itself.

Psychology has numerous approaches to explain motivation we will list them in chronological order.

\subsection{Hedonism}

Psychological hedonism means the individual is motivated by the desire of having the pleasure and avoiding pain [Bruton, 2016]. Some thinkers expressed this view, and neoclassical microeconomics uses the concept as well. [Mandler, 1999] The individual is pain avoiding, and pleasure seeking entity and that is motivating her actions. Hedonism does explain some behaviour patterns, but it is not very useful in clarifying curiosity or hard work for example.

\subsection{Instincts}

Early motivation theories explained behaviour with instincts. These are ingrained behaviour patterns that will activate actions necessary for survival. Instincts are "programmed into" humans and animals and need not be learned. Instinct approaches cannot clarify all actions, for example, learned human behavior and the quest for identifying all of them have found so many that researchers searched for newer explanations.

\subsection{Drive reduction theories}

A drive is a biological determinant of behaviour, which is born with us like instincts, and is activated by deprivation. It is also a "survival" explanation when a human is thirsty s/he will drink when hungry eat when tired sleep. There are primary drives; these are biological and fulfil the body's need for homeostasis - to maintaina stable internal condition. There are secondary drives these are brought about by learning and experience, such as to achieve and be prosperous. Drive reduction theories do not explain why some drives cannot be satisfied but rather seem to increase the need for arousal. Extreme sports are the best example people will expose themselves to danger for the sake of feeling the excitement and exhilaration of being able to do it.

\subsection{Arousal approaches}

Arousal based theories operate on the basis that people want to sustain some degree of stimulation and arousal. When the level of arousal is too low, we will start activities to increase it when it is too high we will do actions to reduce it. This theory clarifies daredevil behaviour but gives no explanation for working hard for a university degree or working out every day for the dream figure. 


\subsection{Incentive approaches}

Feldman calls it "motivation's pull." [2011] The individual's motivation arises from trying to satisfy the desire for something that is worthwhile to strive for, an important job, a status in society. These incentives may work together with internal drives. Incentive approaches cannot entirely explain motivation as we sometimes are active without external incentives, we try to fulfill needs without recognizing specific incentives. There is the "push" behavior of drive reduction theories; one student works very hard for achievement - as a secondary drive - but at the same time becoming a "best student" and getting an award ("pull" of the incentive) may also be active on her.

\subsection{Cognitive approaches}

Cognitive approaches to motivation are interested in people's thought processes, what are the deliberations behind a deed, what trains of thoughts are leading people towards decisions about activities. This line of thinking separatesextrinsic and intrinsic motivation and examines the effect of these on the individual. When we act because we want to achieve a prize that is different from the action we decided to do than our motivation is extrinsic. When we do something because the deedin itself causes us pleasure than our motivation is intrinsic. Extensive research was done to find out whether extrinsic motivation could cause as much satisfaction and psychological well-being as intrinsic motivation. The debate is still on, but results point so far towards that the psychological wellbeing of individuals is supported more by intrinsic than extrinsic motivation. [Ryan, Deci, 2000]

\subsection{Maslow's Hierarchy of Needs}

Although even some famous Organizational Behaviour textbooks mention Maslow's approach as having questionable validity [Robbins, Judge, 2013] this theoryis referred to in psychology textbooks as an important approach. It is very well-known and well respected among practicing managers, not just among psychologists. According to Maslow, human needs have a clear hierarchy that is frequently depicted as a pyramid. The five needs are physiological, safety, social, esteem,self-actualization. The needs have to be satisfied starting with the simplest and going on sequentially to self-actualization. The theory has some attributes we will refrain from detailing here. Although Maslow's framework is relevantintuitively, research was not able to fully validate it. Still this approachis considered as the spawn of other motivation theories such as self-determination theory [Feldman, 2011]

Psychology's aim is to explain human behaviour, and looks at aspects such as hunger and eating, aggression, sexuality, needs for achievement, affiliation, and power. Some of these needs will appear in work motivation as parts of theories that business uses.

\section{Motivation in work psychology}

Work psychology is applied psychology. [Arnold, Randall 2010]. It draws on the ideas of general psychology and has eight areas where it explains behaviour. Motivation is a particular area of work 
psychology and is also connected to quite a few of them such as training, performance appraisal and career development, counseling and personnel development. [Arnold, Randall 2010].

The topic of motivation attracted psychologists and practicing managers as well. In our analysis, we will inspect only some theories that were chosen to highlight our arguments. This article cannot provide the whole scope and literature review of work motivation, and our intention does not lie in this direction.

A classic taxonomy of motivation theories is to group them into two main sets: content and process theories. We will use here a modified version of this classification. The order is early, content, process, and learning-basedtheories. (Griffin and Moorhead [2014])

\subsection{Early theories}

\subsubsection{Taylor's scientific management}

The beginning of the $20^{\text {th }}$ century brought rapid industrialization in the United States. The creation of big organizations happened; railways were built to connect the towns of the country and companies used new technologies that were also a product of this early part of the $20^{\text {th }}$ century. Fast growth needed people. Characteristic of this phase of industrial development that workers who arrived to do jobs in the factories in the US came from agricultural regions or were European immigrants. These people had very little or no education and were destitute. Training them and using them in factories was a challenge for the managers of those companies. [Huczynski, Buchanan 2013]Frederick Winslow Taylor's scientific management offered a solution with using money as an incentive. Without detailing the drawbacks and merits of this approach, we have to mention that the target group consisted of workers for whom money meant a way of escaping from poverty and providing a means for better living. Summarizing: in Taylor's time motivation was about money and in this period, it was a highly successful method.

\subsubsection{The Hawthorne experiments}

These studies are treated as an antithesis to Taylor's approach towards workers; theyare regarded as the first more humanistic approach to employee treatment. These impressive series of social science experiments though were not the first research into worker attitudes. In England in 1917 the Industrial Fatigue Research Board was created, in the United States well before the Hawthorne experiments in 1912, the president of General Electric suggested creating a Department of Applied Psychology to research human needs at the factory. [Hassard, 2012] The Hawthorne studies were carried out at the Hawthorne plant of the Western Electric Company in the US from 1924 till 1932. These studies created a milestone in work psychology as the conclusions are still viewed as valid today. In the studies, researchers proved for the first time that work is a group activity, and the workers' performance depends to a considerable extent on social factors. Money is an important issue but not the only definitive factor in motivation. [Huczynski, Buchanan 2013] 
These new propositions about motivation could also be classified as content theories as they are extensively outcome oriented and research what the employer has to give the employee to induce useful work-related behaviours.

\subsection{Content theories of motivation}

These theories examine what are those needs that have to be satisfied to feel fulfilled, what are those factors that the employer has to provide in the work environment which ensure that employees are striving for those, and their acquisition gives them satisfaction. A non-comprehensive list of these theories:

- Maslow's hierarchy of needs

- Alderfer's ERG theory

- Herzberg's two-factor, or motivation - hygiene theory

- David McClelland's acquired needs theory

- Nohriaet. al. Four drives theory

Based on: Huczynski, Buchanan 2013, and Nohriaet. al.

All these theories explore needs in the employee and offer techniques to satisfy these. The frameworks differ, but the logic is the same in all of them. If the employer can find out the needs of the employee, then the problem of motivation can be solved by using the techniques they offer. When comparing these theories to Taylor's scientific management a striking resemblance hits the researcher: Taylor gave workers money, the new explanationsprovidesome other things, such as recognition, responsibility, possibility to bond with colleagues, defending our territory, providing power. We look for a solution via giving something and do not emphasize the thought processes of the individual. It would be an overstatement to say that they ignore employees' opinions and capacity of evaluation of their needs and the satisfaction of those, but the emphasis is on the "what do you need" and "I will secure that for you and we all be satisfied."

\subsection{Learning based theories of motivation}

Employees will evaluate their actions based on in which way were they encouraged or reinforced after their behaviour. If they got positive reinforcement behaviour would be repeated if they got punishment behaviour levels would be decreased and if nobody notices their enthusiasm and hard work activities will stop. Behavioural intensity will also be increased if the employee finds an opportunity to avoid negative consequences of his/her actions. These are the basic types of reinforcement that are explaining conduct in learning theory. Reinforcement theory is also observed as a motivational theory in literature, as the people will learn from their actions and at the same time they will increase or decrease the frequency of desired activities. (Griffin and Moorhead [2014] and Huczynski, Buchanan [2013])

Although reinforcement theory is treated in Organizational Behavior textbooks as a "process" theory, we cannot regard it as such. Reinforcement theory is based on operant conditioning, and that belongs to the behaviourist school of psychology. Behaviourist theories of learning are based on examining the 
triggers of behaviour and the actual actions, but they do not look at the process between the two as they do not research internal mental states. (McLeod, [2013])

In the world of organizations, this approach is widely used and has a history of being very effective. As a criticism, we could mention that simple conditioning cannot go far and long to sustain complex behaviours and may be very resource dependent (if you started a positive reinforcement program you have to keep it up, otherwise behavioural responses will die out). Still it is a standard management tool. (Huczynski, Buchanan [2013])

\subsection{Process theories of motivation}

Here the emphasis is on how people think, what those processes are in their minds that induce them to act. In these theories, the process of thinking is in focus precisely that phenomenon that is not regarded as possible to study in behaviourist theories. We chose some of these and consciously disregarded constructs of motivation. The list is:

- Equity theory

- Expectancy theory

- Goal setting theory

- Social cognitive theory

- Self-determination theory

The cognitive aspect is the focus, what are those thoughts that go on in the minds of people that induce them to act. The emphasis is different in each theory.

Equity theory stresses justice in organizations people should get what they deserve, and the outcomes of every employee's actions should be equitable. If that does not happen motivation to resolve will be high in the individual.

Expectancy theory gives a lot of rational credits to employees as it assumes that: humans are utility maximizers and pain avoiders, that they have their preferences clear-cut, and can decide how much they have to work and how important rewards are for them. The basic idea of the theory is that an employee will start work if $\mathrm{s} /$ he thinks $\mathrm{s} /$ he can achieve a good result, that result will end up in a reward and the reward has a high value for him/her. (Slocum, Hellriegel, [2011] pp. 175-178)

Goal setting theory is called a "theory" but according to its creator Edwin Locke it is more technique than a formal theory (Locke, [1975], p. 465, cited in Huczynski, Buchanan [2013]). The propositions of the theory are that if the employer sets specific, measurable, attainable and time-related goals (acronym: SMART) and it is done together with the employee, then motivation will be optimal.The advantage of the theory is that it emphasizes feedback as knowledge of results helps the employee to improve. Feedback is criticalin all cognitive theories to a different extent.

Social cognitive theory is based on Albert Bandura's research. The individual will learn via observation and then replicate the act and if the reactions/he got after is positive the act will be repeated if negative then the action will be dropped. Self-efficacy is an integral part of this theory where the individual's beliefs about his/her personal efficacy will influence whether the person will start a 
particular behaviour, how long will s/he endure and how much effort will s/he expend. (Bandura, [1977])

Self-determination theory has recently found its way into business - organizational behaviour textbooks. The theory is a complex metatheory of human motivation and has an extensive research background. We could classify it as a needs-based theory as it states all humans share three needs: the need for autonomy, competence, and relatedness. These have to be satisfied for achieving healthy behaviour and personal well-being. The theory has six mini-theories that together explain the complexity of human motivation. The explanatory value of this complex idea lies in the subtle distinction what extrinsic motivation is and how it becomes intrinsic, moreover in the elegant way of specifying in what conditions the external environment influences behaviour. (Theory, 2016) The theory emphasizes the advantage of intrinsic motivation as it causes more persistence in behaviour, enhanced performance and more endurance in adversity.

\section{Comparison of the emphases of motivation theories in general psychology and work psychology}

The two considerations are similar but still they have some very distinct differences. Work psychology is applied psychology, so the treatment of motivation and the methods are the same, but the emphasis on some aspects is different.

\subsection{Focus}

General psychology's focus is the individual how s/he behaves, it has a descriptive orientation. In work psychology besides this, the outcome of the person's behaviour is also important. In an organization employee behaviour is just one aspect of employee performance. It is an important aspect, but performance is also a function of ability and organizational support. So the performance equation is: Performance $=$ Individual ability $\mathrm{x}$ Individual effort $\mathrm{x}$ Organizational support (Mathis, Jackson, Valentine, [2014])

\subsection{Explanation}

Work psychology concentrates on work behaviours and addresses others only in conjunction with these. The attention is on why an individual would work and deals with related issues such as wellbeing (as in self-determination theory), or enhanced feeling of efficacy (as in self-efficacy theory). General psychology attempts to explain a range of behaviours for example aggression, care for offspring, curiosity, and obesity.

\subsection{Prediction}

In work psychology, the aim of the analysis is to predict how an individual would behave given certain circumstances. The organization's managers need help in finding solutions for their motivational 
problems and theory is an option. In general psychology prediction may be substantial, for example, to determine whether a mother would care for her offspring or not, or in what conditions would people be aggressive, but the description is more of an issue than prediction here, it has less weight.

\subsection{Control of the individual}

Psychological disorders have to be treated people need help in finding mental health and need aid to find happiness and well-being. The point in general psychology is to assist in these and provide assistance to all those who need it. Work psychology's aspect is more mundane: it aids managers to have tools in their hands to control the behavior of employees in the interest of the organization to realize the aims of the company. Companies also need psychologically well-balanced individuals, but it needs them toachieve the objectives of the organization. If the individual's needs are fulfilledin the meantime, the success is double the employee stays longer and adds more value.

\subsection{Explanations}

Although researchers realized already in the middle of the $20^{\text {th }}$ century that there is no "one best way" of managing people somehow the theories that are created since still seem to chase this notion, at least in work psychology, and also in theories that are used by everyday managers. General psychology seems more cautious to deem something to be able to solve all problems of humans. The approach is understandable to defend work psychology and managers. Theories can be interesting mind-games, but managers need simple, fast and efficient solutions to everyday problems, and do not have time or energy to utility maximizing behaviour all the time. If a theory is suitable enough they will use it, if it solves problems they will accept it as helpful and will use it again as long as it works. The problem with this approach is that off-the-shelf solutions have no theoretical base, and they may be fine in one situation and be disastrous in others. Managers need to accept that without not one, but several good theories motivational attempts are deemed unsuccessful and inefficient in the long run.

\begin{tabular}{|l|l|}
\hline General Psychology & Work Psychology \\
\hline $\begin{array}{l}\text { Focuses on the individual } \\
\text { Explains some behaviors }\end{array}$ & $\begin{array}{l}\text { Concentrates on the } \\
\text { outcome of the } \\
\text { individual's behavior }\end{array}$ \\
\hline $\begin{array}{l}\text { Prediction is of less } \\
\text { behavior wht }\end{array}$ & Prediction is key \\
\hline Control may be significant & $\begin{array}{l}\text { Control is of crucial } \\
\text { importance }\end{array}$ \\
\hline
\end{tabular}


$\begin{aligned} & \text { Non-exclusive } \\ & \text { explanations } \\ & \text { way." }\end{aligned}$

Table 1: General psychology versus work psychology

\section{Some unresolved questions - areas of future research}

Motivation is an incredibly well-researched area of psychology even if it sometimes deemed to be a dead end. (Arnold, Randall, [2010])Recent development in other areas of management and clinical neuropsychology renewed interest in the field as these may clarify so far unexplored issues.

\subsection{Bounded rationality}

Managers are intendedly rational, but they succeed only to be boundedly rational according to Herbert Simon (Simon, [1978]). Motivation theories assume people are entirelyrational; theycan assess their priorities, the consequences of their actions and they know what causes them pleasure. After Herbert Simon's research, it is proved that people are not able to do this. Research into systematic errors in human judgment like Kahneman and Twersky's research demonstrated that people do not know what causes them pleasure and they are bad judges of their intentions. (Pressman, [2006]) Investigating how these results could be built into more realistic motivational models would help in creating better solutions for everyday life and not just in work psychology.

\subsection{Motivation and timing}

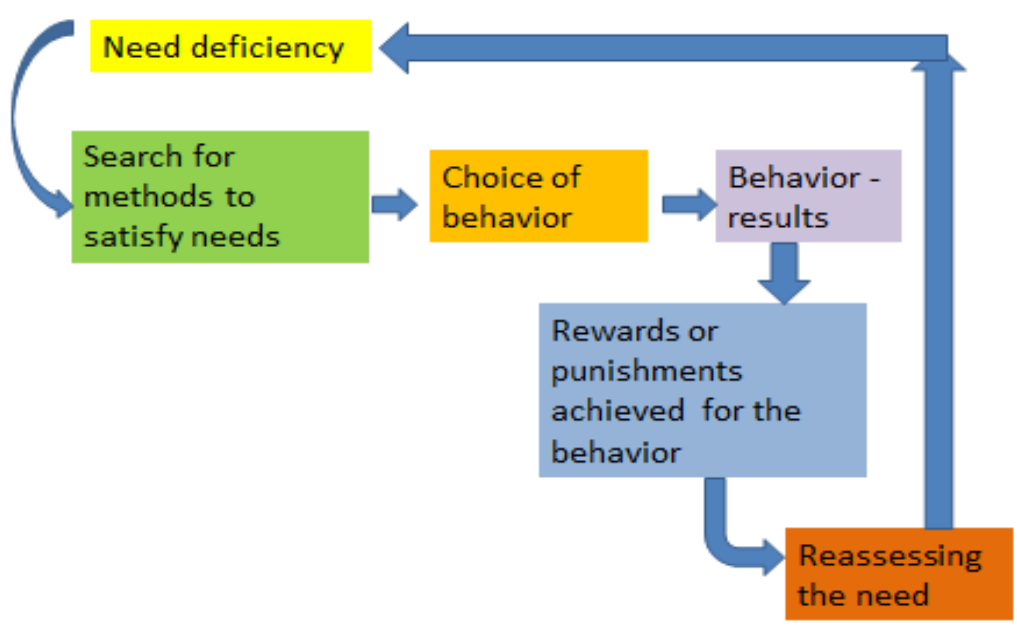

Figure 1: In Griffin and Moorhead [2014] motivation is a circle, a process without an end. Motivational Framework Based on: Griffin, Moorhead, 2014 .p. 91. 
The question is here how long will the effect of motivation last till we reassess the need? Motivational techniques cost money, effort, and these are scarce resources in an organization, especially if they are ineffective. It is a challenge for the future to incorporate time frames into motivation theories.

\subsection{The development of clinical neuropsychology}

Research about addiction proved that long -term cannabis users had lower dopamine levels in the brain. If dopamine levels are lower in the part of the brain which is called striatumthis is linked to less ambition and motivation at theneuronal level. This phenomenon also explains the "a motivational syndrome" in drug users. (Bergland, [2016]) If it turns out that motivation is a question of biochemistry, then the whole approach towards this issue has to be changed. Moreover, it raises other ethical issues. Such as: how can managers induce their employees to take motivational drugs?

\subsection{Extrinsic - intrinsic motivation}

Research proved intrinsic motivation leads to enhanced performance, more happiness, more psychological well-being. The question is: do we have to strive for intrinsic motivation in our working life all the time? Organismic IntegrationTheory, which is one of the mini-theories of Self-determination theory explains that we can achieve high levels of motivation, even if it is extrinsic. What is the threshold we have to cross to motivate our employees? Is it worth striving for intrinsic motivation, or does integrated regulation give us adequate performance? Frederick Winslow Taylor was blamed that he never considered the health and psychological well-being of the workers he worked with. It seems today we continually push our employees towards happiness and intrinsic motivation the "flow" experience of Csíkszentmihályi. (MihalyCsikszentmihalyi...[2016]) It would be interesting to compute the costs of achieving a "flow" condition and comparing it with integrated regulation and the attained business results. Moreover, we cannot be sure employees wish to reach flow in the workplace; they might strive for it elsewhere in their lives.

\section{Concluding comments}

Motivation is still a fascinating topic in the $21^{\text {st }}$ century. Research results tend to steer us towards multidisciplinary research where the work of general and work psychology and clinical neuropsychology create new results and aid practicing managers in designing effective motivational strategies for their employees. Business practices and experience of our everyday lives seem to be enlightening the scientific experience and adding value to research and guiding us towards aricher picture of the human.

\section{References}

[1] J. Arnold, R. Randall (2010), Work Psychology, Pearson Education Limited, Harlow, England 
[2] A. Bandura (1977), Self-efficacy: toward a unifying theory of behavioral change, in: Psychological Review, 1977, Vol. 84. No. 2 pp. 191-215.

[3] C. Bergland (2016), Does Long-Term Cannabis Use Stifle Motivation?, in: Psychology Today accessed at: https://www.psychologytoday.com/blog/the-athletes-way/201307/doeslong-term-cannabis-use-stifle-motivation 08032016

[4] J. F. Binning (2016), Construct, in: Encyclopedia Britannica accessed at: http://www.britannica.com/science/construct 27.02. 2016

[5] S. V. Bruton (2016), Psychological hedonismin: Encyclopedia Britannica accessed at, http://www.britannica.com/topic/psychological-hedonism 20.03.2016

[6] R. S. Feldman (2011), Understanding Psychology, McGraw-Hill, New York

[7] S. Graham, B. Weiner (1996), Theories and Principles of Motivation, in: Berliner, David C. [Ed]; Calfee, Robert C. [Ed], [1996]. Handbook of educational psychology. , [pp. 63-84]. New York, NY, US: Macmillan Library Reference Usa; London, England: Prentice Hall International, $\mathrm{x}, 1996,1071 \mathrm{pp}$.

[8] A. Gősiné Greguss, É. Bányai (2006), A motiváció [Motivation], in: Oláh, A.: Pszichológiaialapismeretek [Basic Psychology] BölcsészKonzorcium, pp: 323-369

[9] R. W. Griffin, G. Moorhead (2014), Organizational Behavior South Western Cengage Learning, Mason USA 11th edition

[10] J. Hassard (2012), Rethinking the Hawthorne Studies: The Western Electric research in, its social, political and historical context, in: Human Relations, 0[0] pp: 1-31

[11] A. A. Huczynski, D. A. Buchanan (2013), Organizational behavior Pearson education, Harlow, 8th edition

[12] E. A. Locke (1975), Personnel attitudes and motivation, in: Annual Review of Psychology, Vol. 26, pp. 457-480.

[13] M. Mandler (1999), Dilemmas in Economic Theory, Oxford University Press

[14] R. L. Mathis, J. H. Jackson, S. R. Valentine (2014), Human Resource Management, Cengage Learning, Stamford, USA 14th edition

[15] J. McAuley, J. Duberley, P. Johnson (2007), Organization Theory, Prentice Hall Financial Times, Pearson Education, Harlow England

[16] S. McLeod (2013), Behaviorist Approach accessed, at:http://www.simplypsychology.org/behaviorism.html 23032016

[17] N. Nohria, B. Goysberg, L. Lee (2008), Employee Motivation A Powerful New Model, in: Harvard Business Review, July-August

[18] C. C. Pinder (1998), Work motivation in organizational behaviour, Upper Saddle River, NJ: Prentice Hall 
[19] S. Pressman (2006), Kahneman, Twersky, and Institutional Economics, in: Journal of Economic Issues, Vol XL, No. 2. pp. 501-506.

[20] A. Richardson, E. Terrel (2008), Apple Computer Inc., accessed at:https://www.loc.gov/rr/business/businesshistory/April/apple.html 20.03.2016

[21] R. M. Ryan, E. L. Deci (2000), Self-determination Theory and the Facilitation of Intrinsic Motivation, Social development and Well-being, in: American Psychologist, Vol 55. No. 1 pp.68-78

[22] S. P. Robbins, T. A. Judge (2013), Organizational behavior, Pearson education 15th edition

[23] H. Simon (1978), Rational Decision-Making in Business Organizations, Nobel Prize lecture, accessed at: http://www.nobelprize.org/nobel_prizes/economicsciences/laureates/1978/simon-lecture.pdf23 032016

[24] J. W. Jr. Slocum, D. Hellriegel (2011), Principles of Organizational Behavior, South-Western, Cengage Learning, International Edition

[25] Theory (2016), accessed at: http://selfdeterminationtheory.org/theory/ 23032016

[26] M. Csikszentmihalyi (2016), accessed at: http://www.pursuit-of-happiness.org/history-ofhappiness/mihaly-csikszentmihalyi/ 